\title{
الكلمة والجملة في اللغة العربية
}

\section{Ahmad Munawwir}

Universitas Islam Negeri Alauddin Makassar

E-mail: ahmad.munawwir@uin-alauddin.ac.id

DOI: $10.24252 /$ saa.v8i2.17958

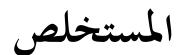

يبحث هذا البحث في الكلمة والجملة في اللغة العربية وأنواعهما، إذ يتركز على شيئين: 1) ما هي الكلمة وما تقسيماتا، و2) ما

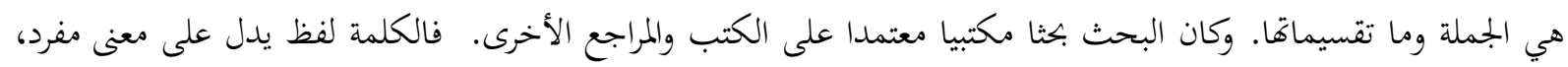

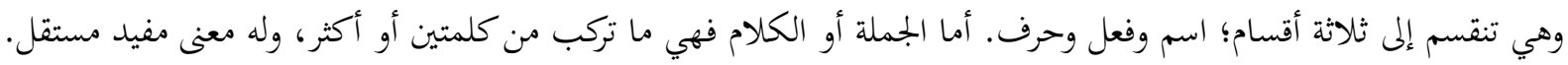

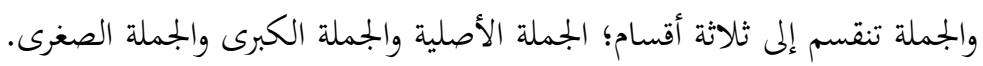

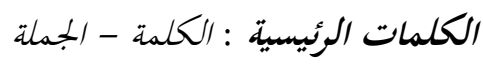

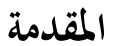

إن اللغة العربية هي الكلمات التي يعبر بها العرب عن أغراضطم ، وقد وصلت إلينا من طريق النقل ، ولمها

خشي أهل العربية من ضياعها بعد أن اختلطوا بالأعاجم دونوها في المعاجم أو القواميس وأصَّلوا لها أصولاً تحفظها من الخطأ ووضعوا لها قواعد تحكمها ، وتسمى هذه القاعدة وتلك الأصول (العلوم العربية). 1

فالعلوم العربية هي العلوم التي يتوصل بها إلى عصمة اللسان والقلم عن الخطأ ، وهي ثلاثة عشر علماً ، الصرف والإعراب والرسم والمعاني والبيان والبديع والعروض والقوافي وقرض الشعر والإنشاء والخطابة وتاريخ الأدب

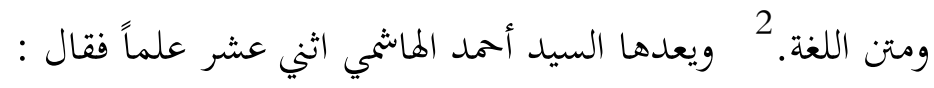

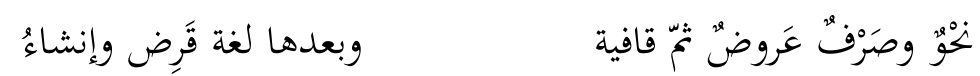

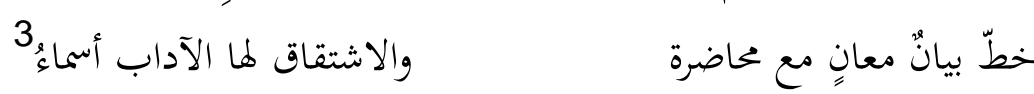

هذه العلوم والقواعد العربية يجمعها علمان ، يخص أولمما الكلمات العربية وهي مفردة ، ويخص ثانيهما هذه الكلمات وهي في حالة تركيب. وكلا العلمين من أهم علوم العربية ، لكل معنيّ بصحة القراءة والكتابة صوغاً

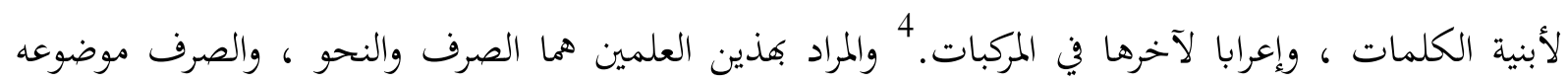

1مصطفى الغلاييني ، جامع الدروس العربية ، المكتبة العصرية ، 1993م ، ج ج 1 ، ص ص 7 ، 7

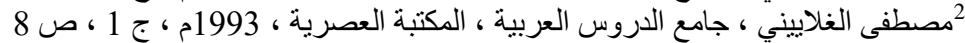

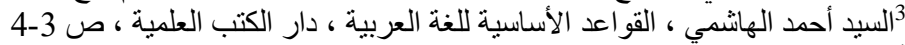
4سليمان فياض ، النحو العصري ، مركز الأهر ام ، الطبعة الأولى ، 1995 م ، ص صل 13 
الكلمة من حيث مبانيها ، والنحو موضوعه الكلمات التي تتركب في الجملة من حيث نظام تركيبها ووظائفها في الجملة.

إذن فمعرفة الكلمة والجملة هي أساس ومدخل لدراسة العلوم العربية الأخرى. فعلى كل دارس اللغة

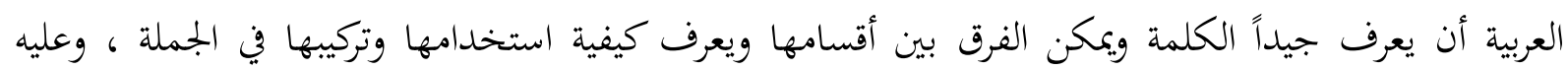
أيضًا أن يعرف جيدًا الجملة حتى يتمكن من إنشاء جملة صحيحة ويستطيع أن يبين الفرق بين الكلمة والجملة.

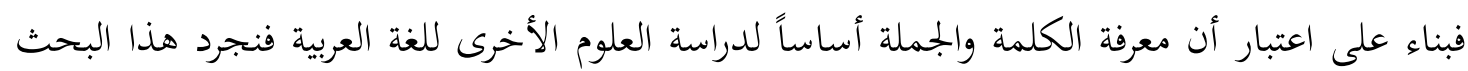

$$
\begin{array}{r}
\text { 2- } \\
\text { 2 }
\end{array}
$$

البحث

أ. الكلمة وأقسامها في اللغة العربية

$$
\text { 1. تعريف الكلمة }
$$

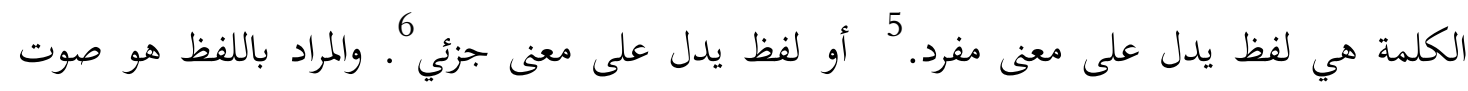

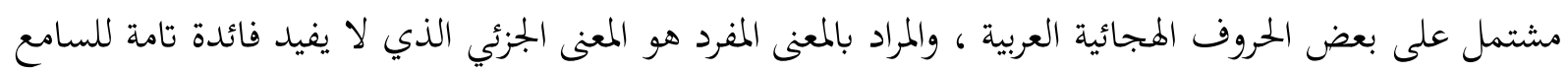
، ولا يحسن السكوت عليه المتكلم.

وذلك مثل كلمة (قَلمّ) فإنها لفظ مشتمل على ثلاثة أحرف من الحروف الهجائية العربية ، وتفيد معنى جزئًا لأنه لا تفيد إلا على أنه اسم لشيء معين.

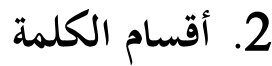

وأقسام الكلمة ثلاثة : اسم وفعل وحرف. ويرجع هذا التقسيم إلى اعتبارين أحدهما باعتبار الدلالة

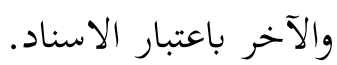

فالتقسيم باعتبار الدلالة : أن الكلمة إن دلت على معنى في نفسها غير مقترن بزمان فهي الاسم ، وإن

$$
\text { اقترن بزمان فهي الفعل ، وإن لم تدل على معنى في نفسها بل في غيرها فهي الحرف. }
$$

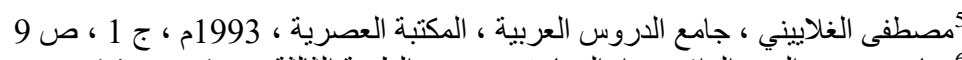

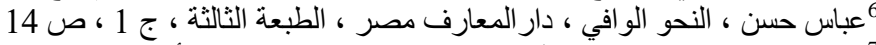
7قاضي القضاة بهاء الدين عبدالله بن عقيل ، شرح ابن عقيل على ألفية ابن مالك ، الطبعة العشرون ، دار التراث القاهرة ، 1980م ، ج 1 ، ص ص 
والثاني هو التقسيم باعتبار الاسناد ، فإن الكلمة منها ما يصح أن يكون ركناً للاسناد ومنها ما لا يصح

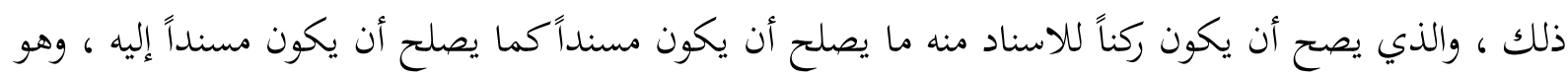

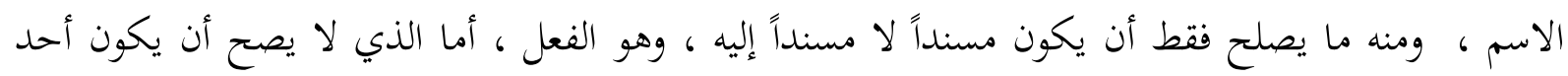
طري الاسناد فهو الحرف.

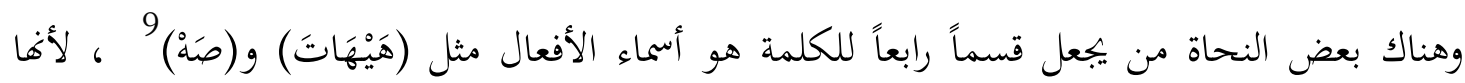

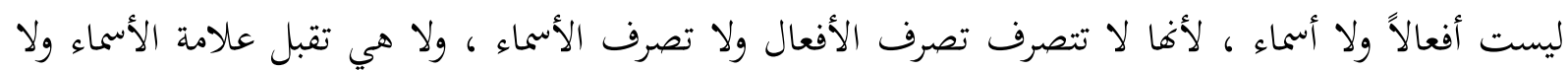

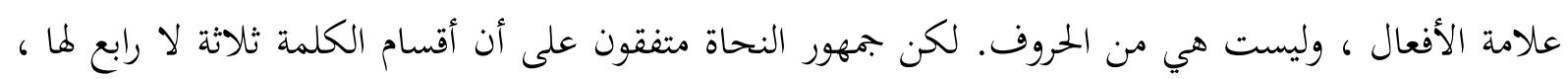

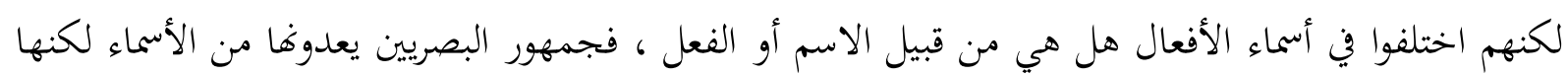

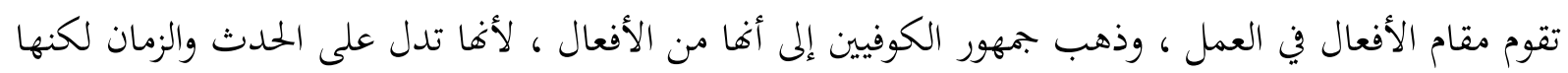
جامدة لا تتصرف ، فهي ك (ليس) و(عسى) ونوهما. 10 والآن سنخوض في تفصيل أقسام الكلمة ببيان التعريف والعلامة والخصائص والأنواع لكل من هذه

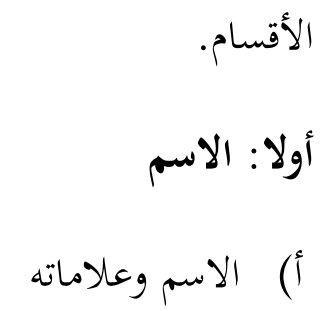

وهو لفظ يدل على معنى في نفسه غير مقترن بزمان ، كخالدٍ وفرسٍ وعصفورٍ . 11 وعلاماته كثيرة ، وأشهرها خمسة ، منها أربعة لفظية وهي:

1) الجرّ بالكسرة التي يحدثها العامل ، وعامل الجر قد يكون حرفاً أو إضافة ، مثل (بسم الله) فالاسم ججرور

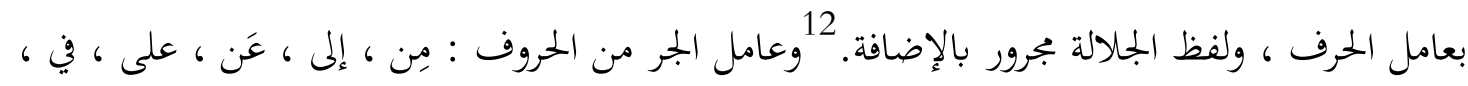

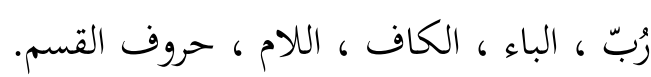

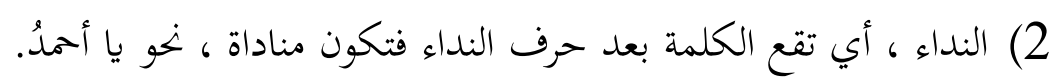
3) دخول (ال) المعرفة كالرجل ، أو (ال) الزائدة كالعبّاس.

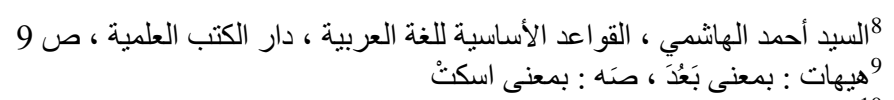
10 محمد محيي : الدين عبدالحميد ، منحة الجليل بتحقيق شرح ابن عقيل ، مطبوع بحاثية كتاب شرح ابن عقيل لقاضي القضاة بهاء الدين عبدالله بن

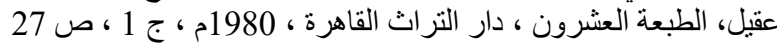

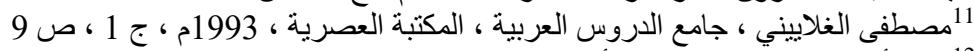
12 السيد أحمد الهاشمي ، القواعد الأساسية للغة العربية ، دار الكتب العلمية ، ص 14 
4) التنوين ، وهو نون ساكنة زائدة تلحق أواخر الأسماء لفظاً ، وتفارقها خطاً. 13 ك(كتابُ) و(سيبويهٍ)

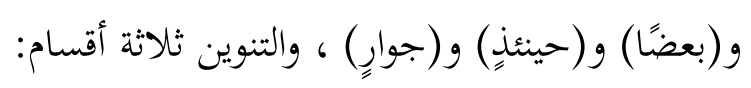

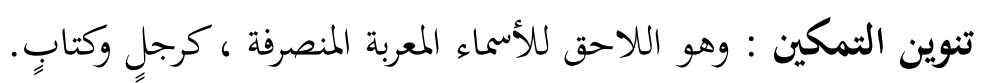

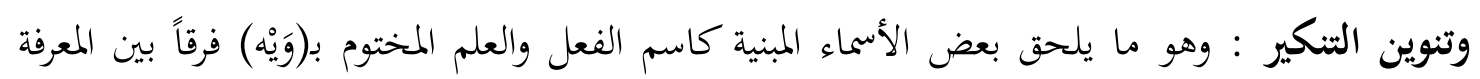

$$
\text { منهما والنكرة ، كصَّه وسيبويهٍ. }
$$

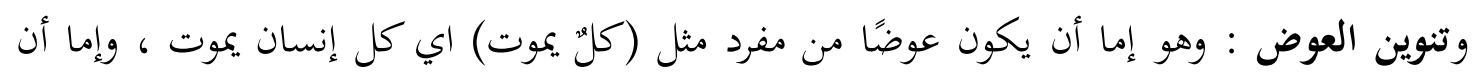

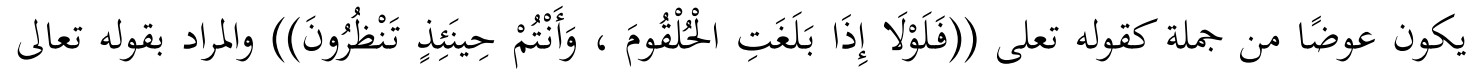

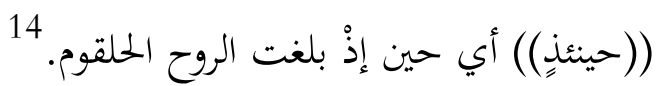

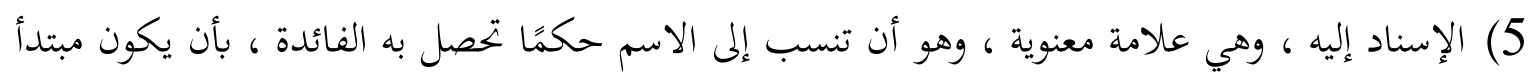

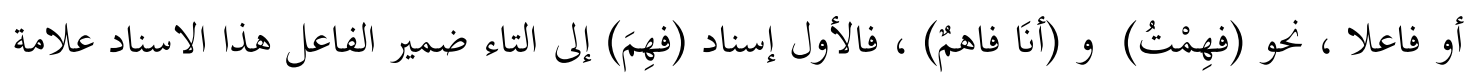

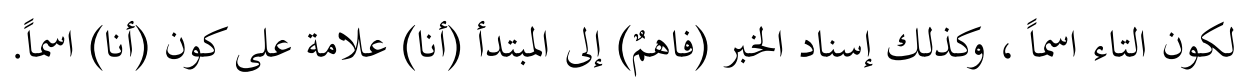

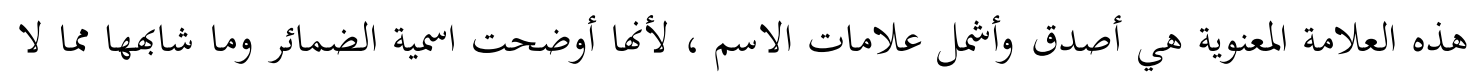
تدخل عليه العلامات اللفظية المتقدمة. 15

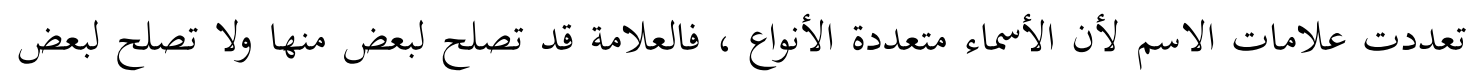

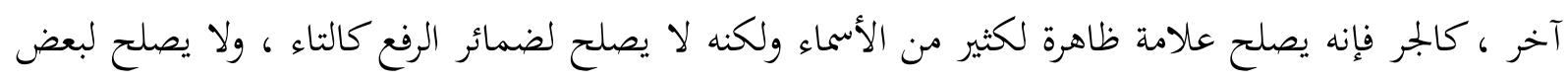

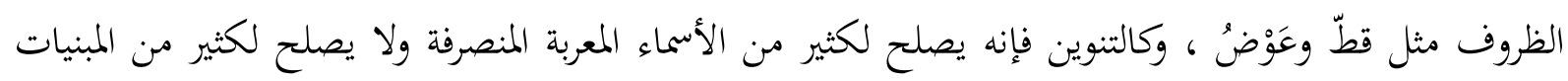

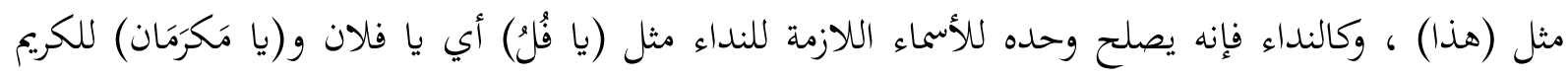

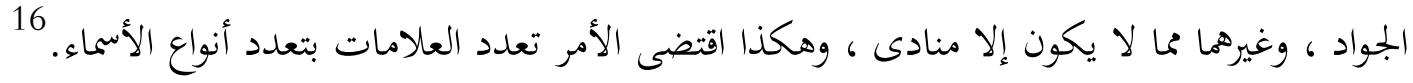

$$
\text { ولاسم علامات أخرى ، أهمها : }
$$

1) أن يعود عليه الضمير ، مثل جاء المحتُسِنُ ، في (المحسن) ضمير ، والمعنى جاء الذي هو محسن ، ولهذا

$$
\text { قالوا (ال) هنا اسم موصول. }
$$

2) أن يكون مجموعًا ، مثل (مفاتيح الحضارة بيد علماء بارعين ، وهبوا أنفسهم للعلم ودراساته) ، فكون اللفظ جمعًا خاصة من خواص الأسماء.

3) أن يكون مصغُّرًا ، لأن التصغير من خواص الأسماء كذلك ، مثل : حسين أجرأ من أخيه الحسن. 
4) أن يبدل منه اسم صريح ، مثل : كيف عليُّ؟ أصيحيحُ أم مريضٌٌ؟ ، فكلمة (صحيح) اسم واضح الاسمية

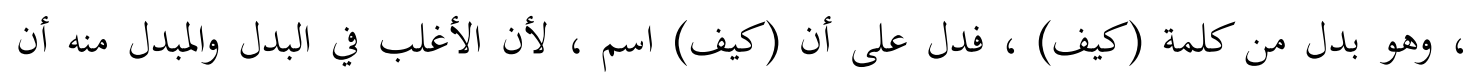

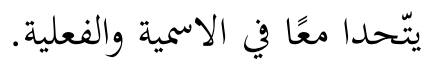

5) أن يكون لفظه موافقًا لوزن اسم آخر ، لا خلاف في اسميته ، ك(نَزال) فإنه موافق في اللفظ لوزن (حَذامِم)

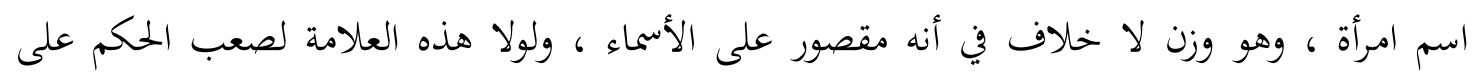

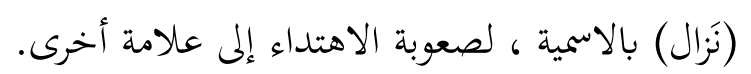

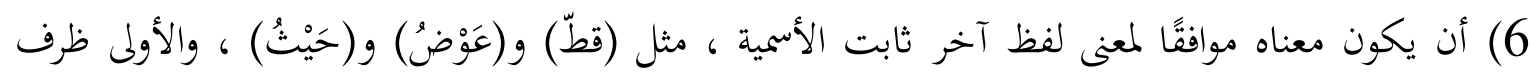

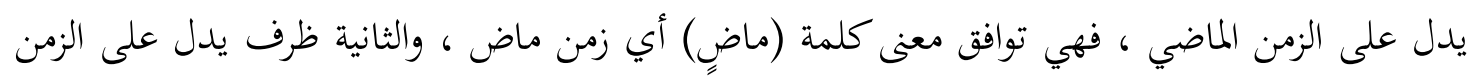

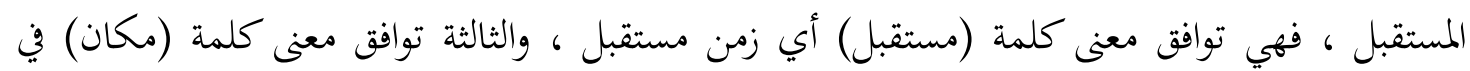

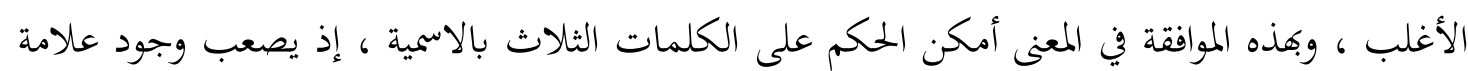
أخرى.

$$
\text { ب) خصائص الاسم }
$$

1) الاسناد ، أي لا يكون المسند إليه إلا اسم ، لأن الاسم هو الركن الأساسي للكلام ، به يقوم وعليه

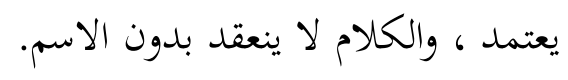

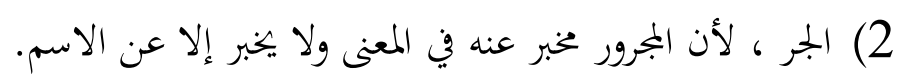

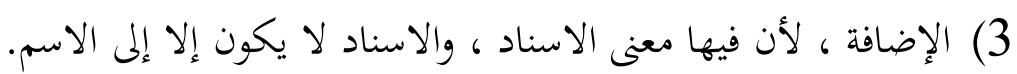

4) ال المعرفة ، لأن أصلها للتعريف وهو خاص بالاسم.

5) النداء ، لأن المنادى في الأصل هو مفعول به ، والمعفولية خاصة بالاسبم.

$$
\begin{aligned}
& \text { 6) التنوين ، فلا تنوين لغير الاسم. } 18 \\
& \text { 7) التصغير ، فلا يُغصَّر غير الاسم. } \\
& \text { 8) الجمع ، فلا يجمع غير الاسم. } 19 \\
& \text { ج) أنواع الاسم }
\end{aligned}
$$

هناك عدة تقسيمات للاسم ، ومن أهمها نذكر التقسيم من حيث ظهور معناه أو عدمه ، والتقسيم من حيث العموم والخصوص. 
التقسيم الأول : فالاسم من حيث ظهور معناه أو عدم الظهور ينقسم إلى ثلاثة أنواع : مُظهَر ، ومُضمَر ، ومُبْهَم.

1) المظهر هو ما يدل على معناه من غير حاجة إلى قرينة ، كسعد وسعاد ، ويدخل في هذا النوع كثير من

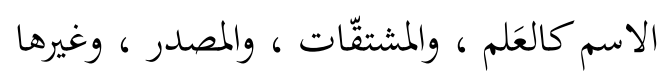

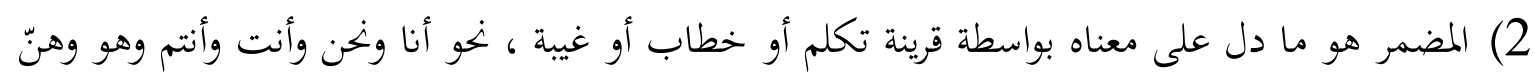

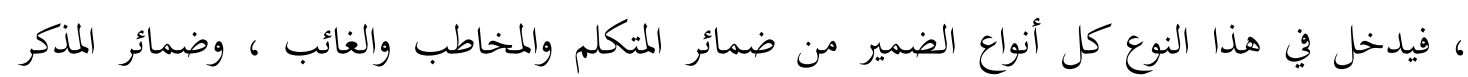
والمؤنث ، وضمائر المفرد والمثنى والمجموع ، والضمائر المتصلة والمنفصلة.

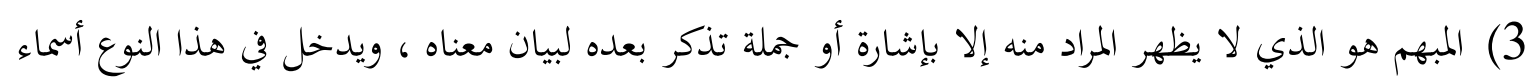

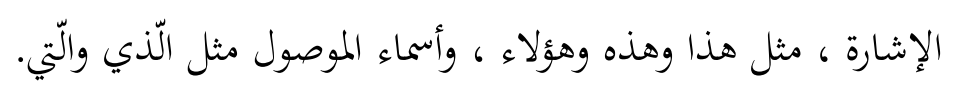

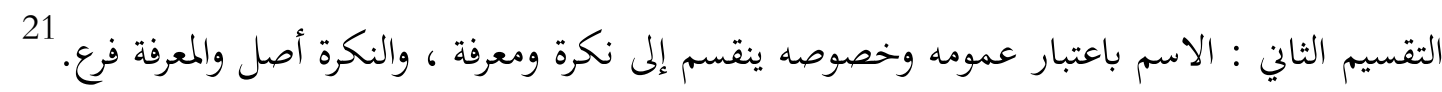

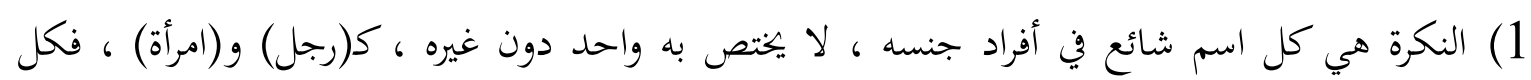

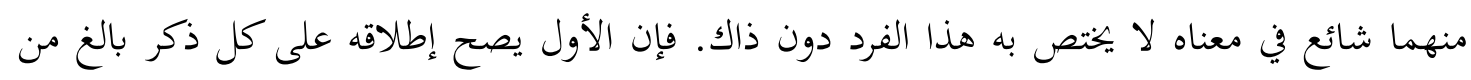
بني آدم ، والثاني يصح إطلاقه على كل أنثى بالغة من بني آدم. فالنكرة هي ما لا يفهم منها معين.

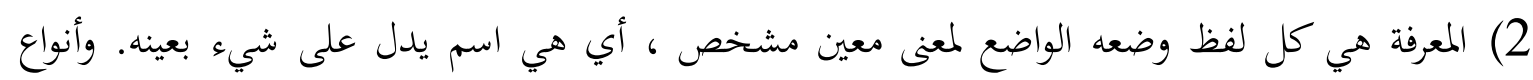

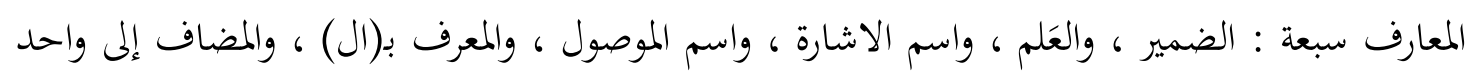
منها إضافة معنوية ، والمنادى.

$$
\begin{aligned}
& \text { والتقسيمات الأخرى للأسماء منها: } \\
& \text { 1) المذكر والمؤنث : مثل كتاب ، ومحبرة }
\end{aligned}
$$

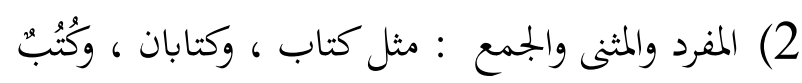

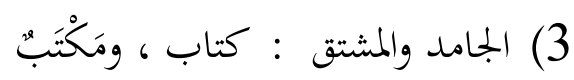

$$
\begin{aligned}
& \text { 4) المقصور والمنقوص والصحيح والممدود. }
\end{aligned}
$$

فالمقصور هو كل اسم معرب آخره ألف لازمة كتبت ألفًا أو رسمت ياء مفتوح ما قبلها ، مثل هدى ولمد

$$
\text { وأعلى. }
$$

والمنقوص هو كل اسم معرب آخره ياء لازمة مكسور ما قبلها ، مثل الداعي والقاضِي.

ا20 السيد أحمد الهاثمي ، القو اعد الأساسية للغة العربية ، دار الكتب العلمية ، ص 16

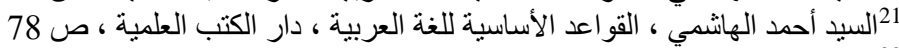

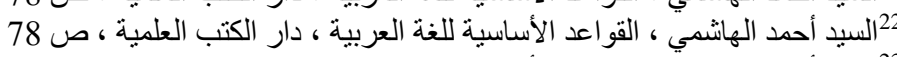

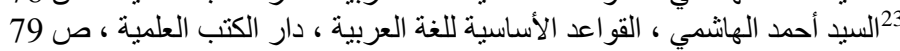




$$
\text { والصحيح هو كل اسم معرب ليس مقصورًا ولا منقوصًا ، مثل كتابٌ ومنزلٌ ولهوٌ. }
$$

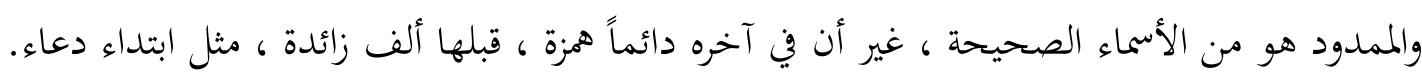

\section{ثانيا: الفعل}

الفعل عند اللغويين هو ما دل على الحدث ، وهو التعريف اللغوي. أما المعنى الاصطلاحي للفعل هو ما

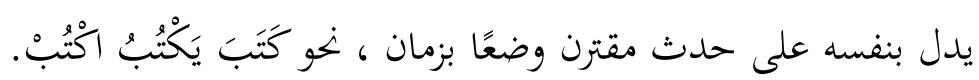

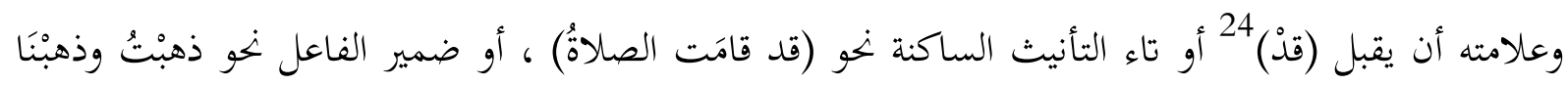

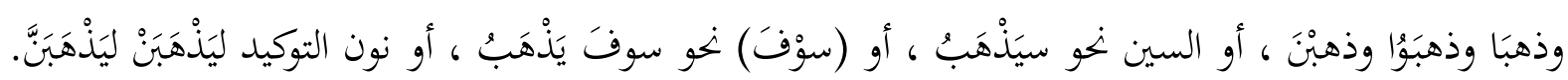

$$
\text { أ) الفعل الماضي }
$$

الفعل الماضي هو ما دل على حدث وقع في الزمان الذي قبل زمان التكلم ، نحو كَتَبَ وأَحْسَنَ

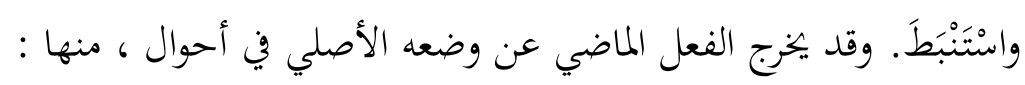

1) قد يدل الفعل الماضي على الزمن الحالي إذا استُعْمل في العقود ، نحو بِعْتُكَكَ هذا الكتاب.

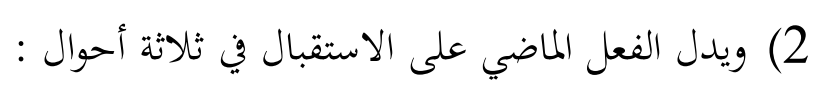

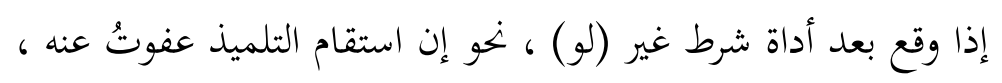

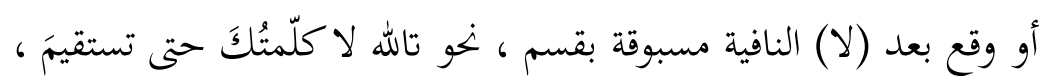
أو كان الفعل الماضي للدعاء، نخو رممه الله ، رضي الله عنه.

$$
\begin{aligned}
& \text { ولملفعل الماضي ثلاث علامات تحتص به. } \\
& \text { تاء الفاعل ، نحو كتبنتُ وكتبنتَّ. }
\end{aligned}
$$

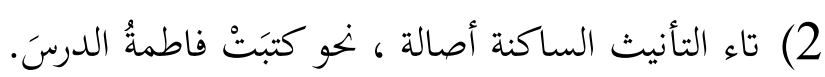

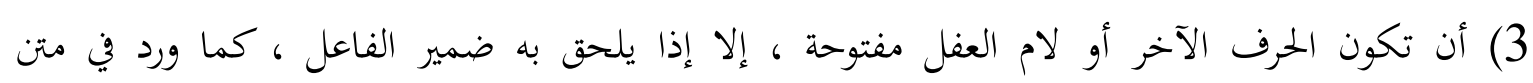

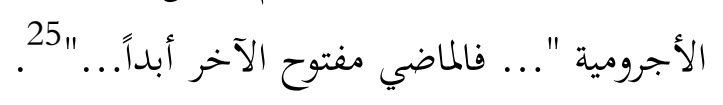

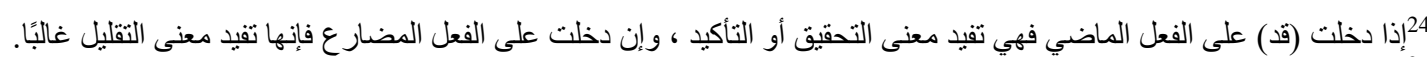

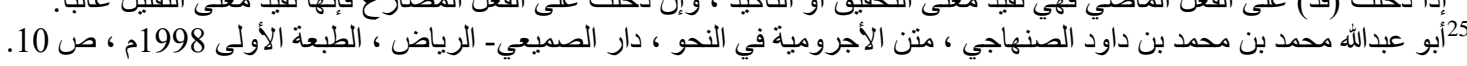




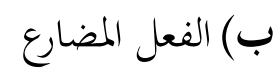

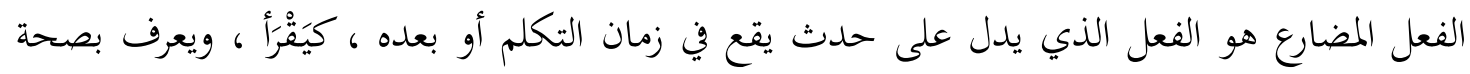

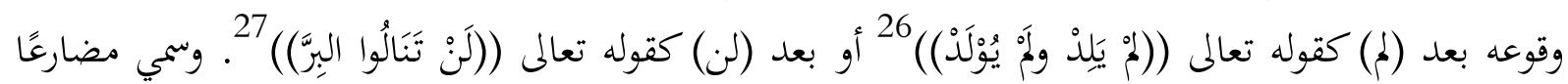

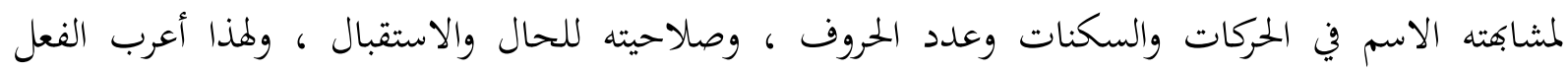
28 المضارع.

$$
\text { وعلامته المختصة به : }
$$

1) السين وسوف : يدلان على التنفيس ومعناه الاستقبال ، إلا أن السين للاستقبال القريب ، وسوف

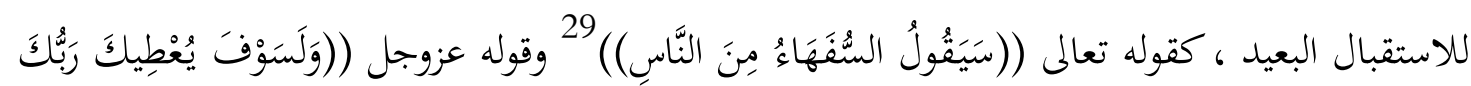

$$
\text { فَتَرْضَنَن) }
$$

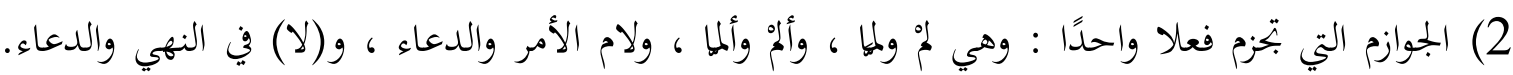

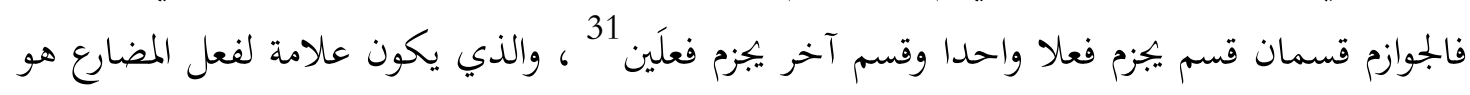
القسم الأول فقط دون الثاني.

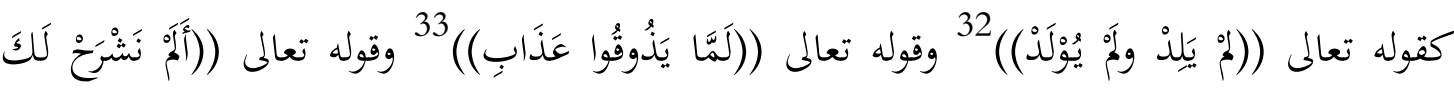

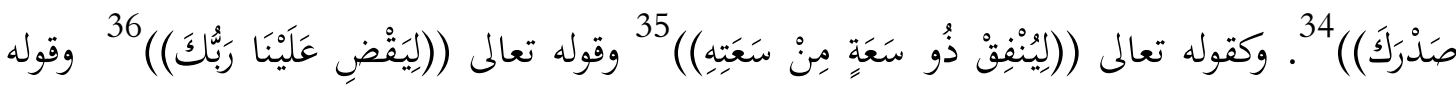

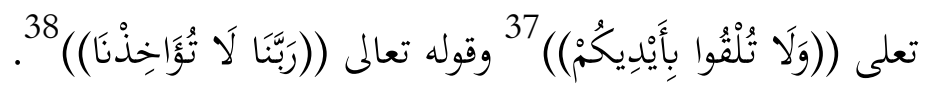

3) وبعض النواصب : مثل لَنْ وكُيْ.

ف(لن) هي حرف ينصب المضارع وينفي معناه ويصيره خالصاً للاستقبال 39 ، كقوله تعالى ((لَنْ تَنَالُوا البِّر)) (40 ، وأما (كيْ) فيشترط في النصب بها من غير تقدير (أنْ) أن تكون مصدرية ، وهي التي تتقدم

$$
\begin{aligned}
& \text { 26 الثرآن الكريم ، سورة الاخلاص ، الآية رقم } 3
\end{aligned}
$$

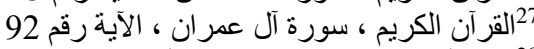

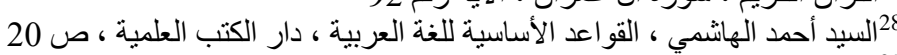

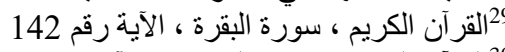

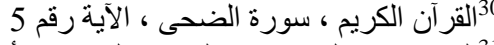

$$
\begin{aligned}
& \text { 313 الثيخ حسن الكفراوي ، الثرح على متن الأجرومية ، مكاتب سليمان مرعي ، سنغافورة- فينغ- كوت بهارو ، ص } 49 .
\end{aligned}
$$

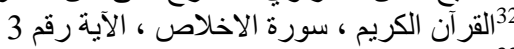

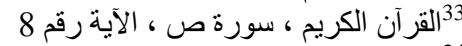

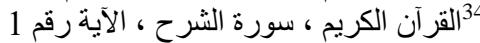

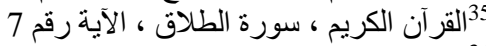

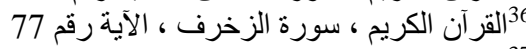

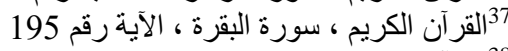

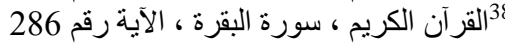

$$
\begin{aligned}
& \text { 39 الثيخ حسن الكفر اوي ، الثر ح على متن الأجرومية ، مكاتب سليمان مرعي ، سنغافورة- فينغ- كوت بهارو ، ص } 44
\end{aligned}
$$

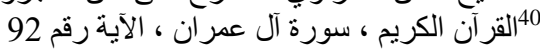




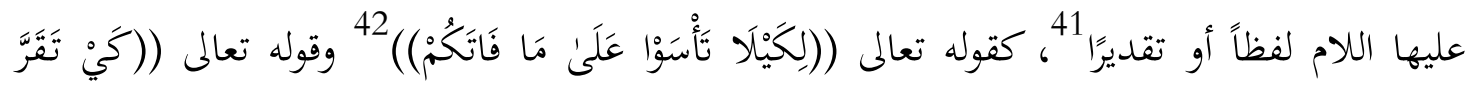

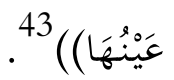

44: وفعل المضارع بأصل وضعه صالح للحال والاستقبال ، ولا يتعين لأحدهما إلا بععينات خاصة 1 45

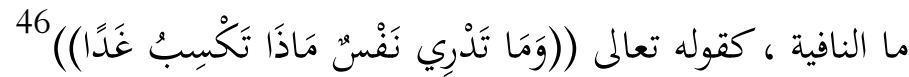

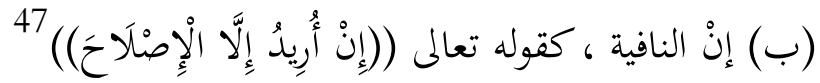

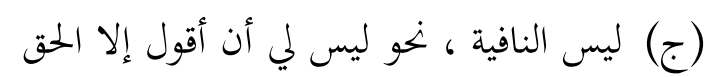

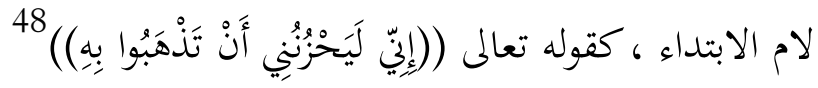

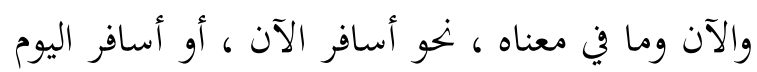
49

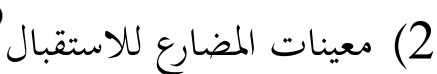

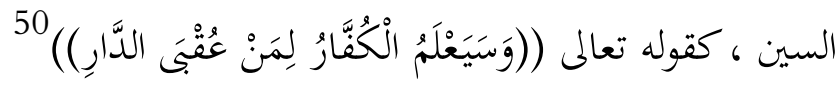

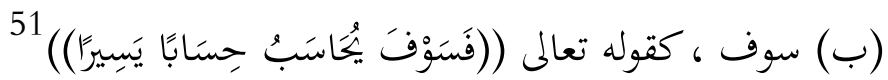

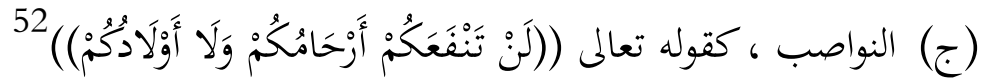

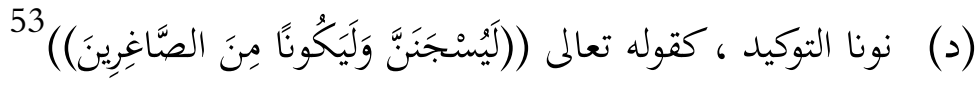

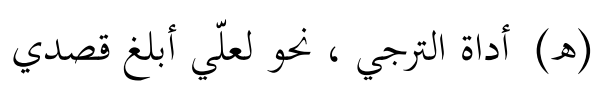

54 : انقلاب المضارع للماضي ، وينقلب فعل المضارع إلى معنى الفعل الماضي بالأدوات الآتية

$$
\begin{aligned}
& \text { (لامْ) الجازمة ، نحو لمُ يقُمْ بالواجب ، وزرتك ولم تكن في الدار. } \\
& \text { (ب) (ملما) الجازمة ، نحو لما يثمر البستان ، وقطفت الثمرة ولما تنضج. }
\end{aligned}
$$

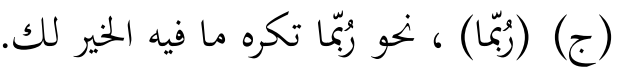

14 الثيخ حسن الكفر اوي ، الثر ح على متن الأجرومية ، مكاتب سليمان مرعي ، سنغافورة- فينغ كوت بهارو ، ص 45

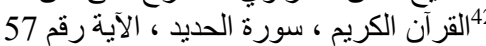
33

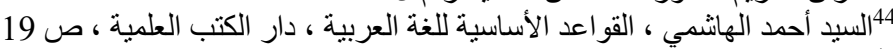

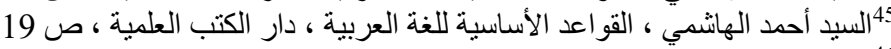

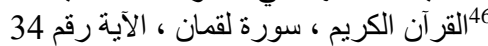

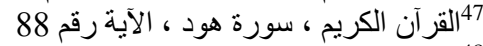
48 القرآن الكريم ، سورة يوسف ، سورد ، الآية رقم 13

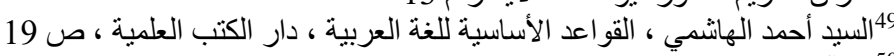

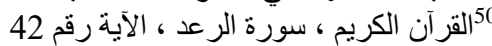

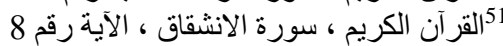
32

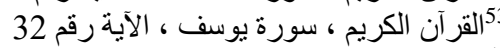
54 السيد أحمد الهانمي ، القو اعد الأساسية للغة العربية ، دار الكتب العلمية ، ص 20 


$$
\text { ج) فعل الأمر }
$$

الأمر هو ما يطلب به حدوث شيء في المستقبل ، نغو : إسمَعْ وانصرْ ودَعْ وقِ.

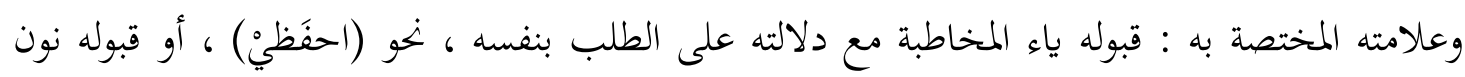

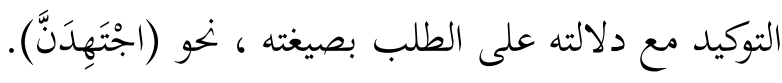

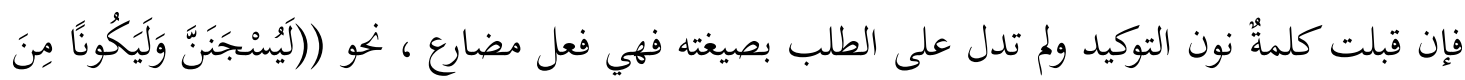

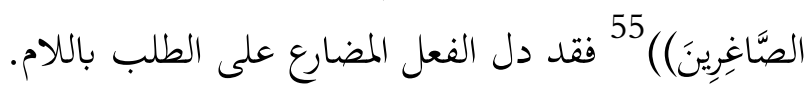

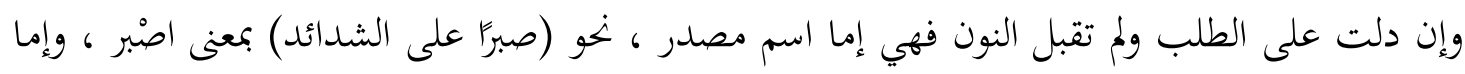

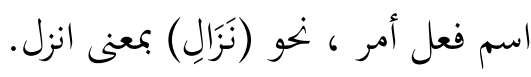

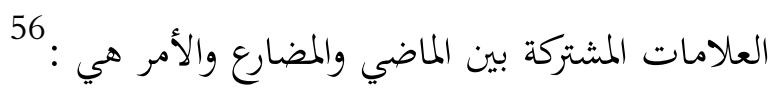

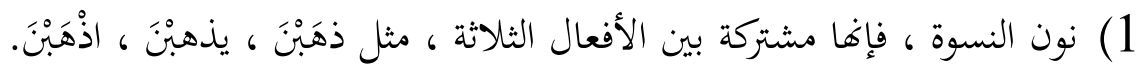

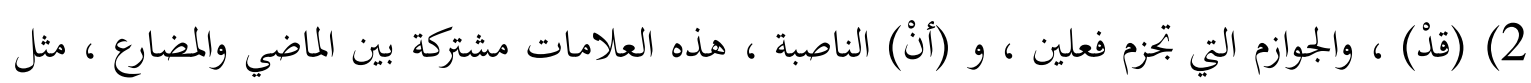

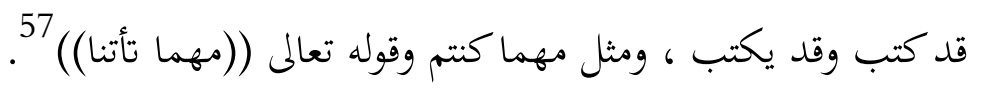

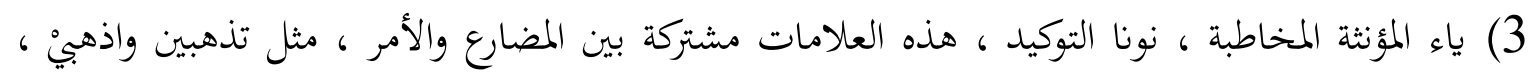

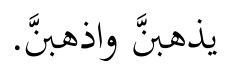

$$
\text { ثالثا : الحرف }
$$

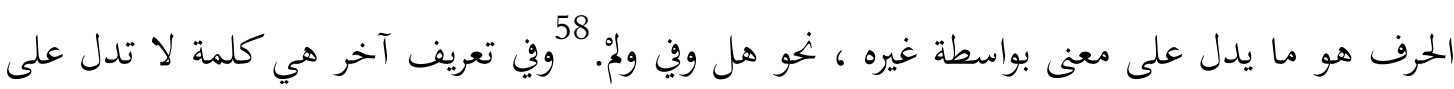

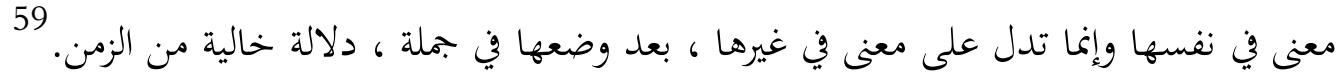

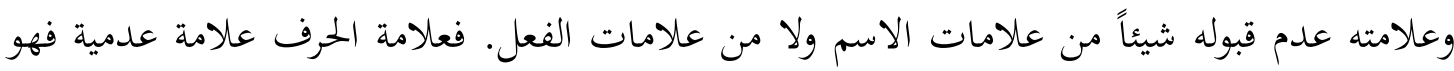

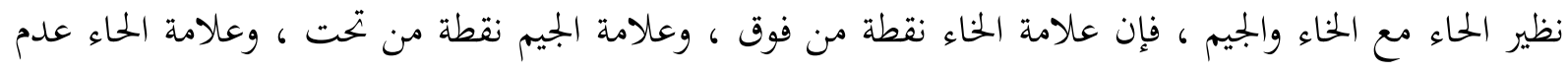
النقط رأساً. وأنواعه ثلاثة:

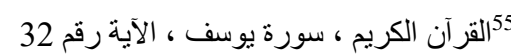

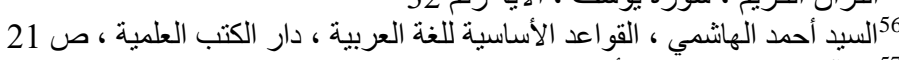
57 57 القرآن الكريم ، سورة الأعراف ، الأبد الآية رقم 132

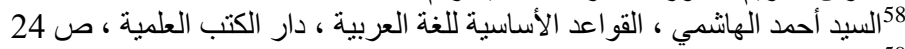

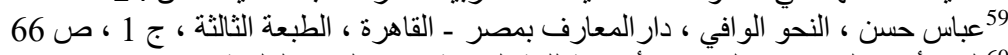
60 60 السيد أحمد الهناشمي ، القو أعد الأساسية للغة العربية ، دار الكتب العلمية ، ص 24 
أ) ما يختص بالأسماء ، فيعمل فيها ، كحرف الجر مثل (في) ، نغو دخلت في المدرسة ، والأحرف التي

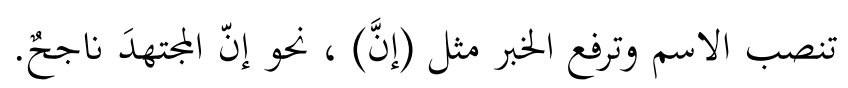

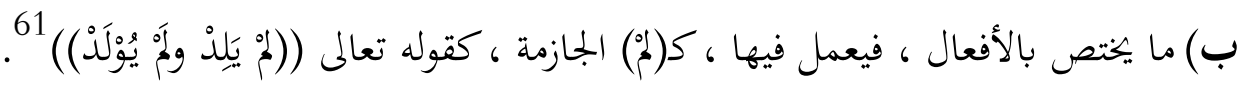

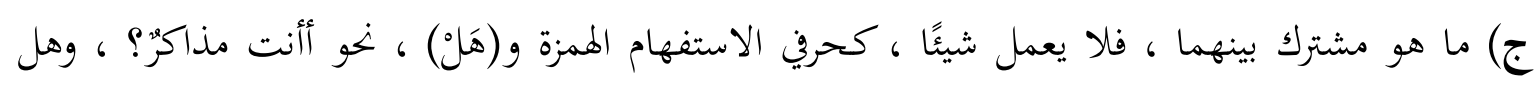

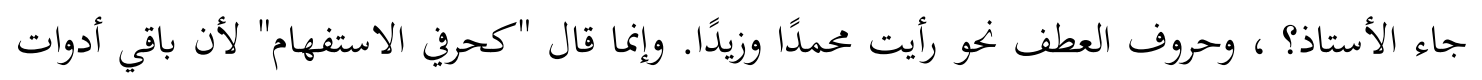

$$
\text { الاستفهام أسماء. }
$$

\section{ب. الجملة في اللغة العربية. \\ 1. تعريف الجملة}

الجملة أو الكلام هي ما تركب من كلمتين أو أكثر، وله معنى مفيد مستقل، مثل أقبلَ ضيف، فازَ طالبٌ نبيهُ، لنْ يُهْمِلَ عاقلُ واجبًا.

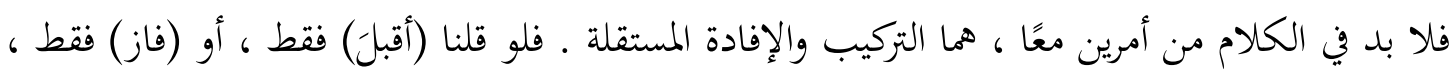

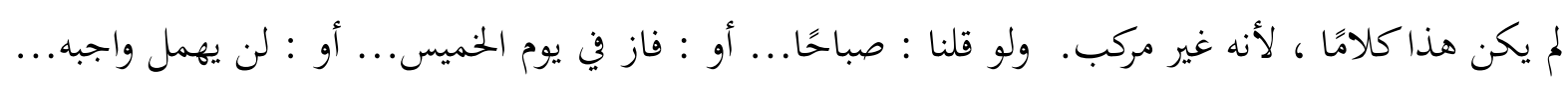

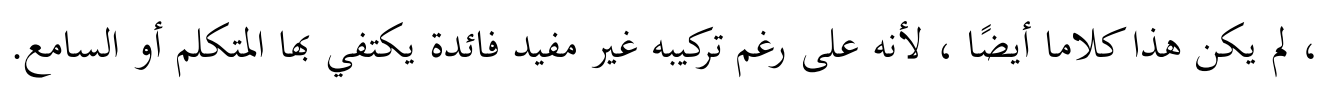

وليس من اللازم في التركيب المفيد أن تكون الكلمتان ظاهرتين في النطق ، بل يكفي أن تكون إحداهما

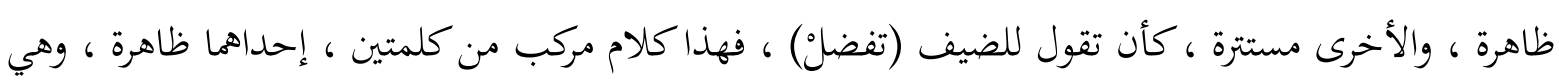

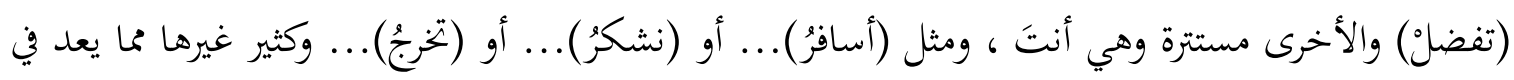

$$
\begin{aligned}
& \text { الواقع كلاماً ، وإن كان ظاهره أنه مفرد. }
\end{aligned}
$$

الكلام مرادف للجملة ، والدليل على هذا قول ابن مالك في ألفيته وشارحها :كلامنا لفظ مفيد

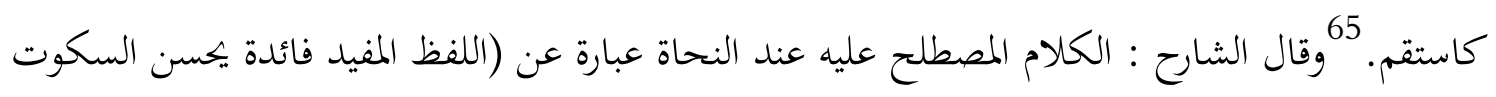

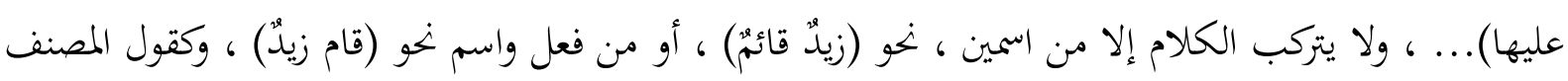

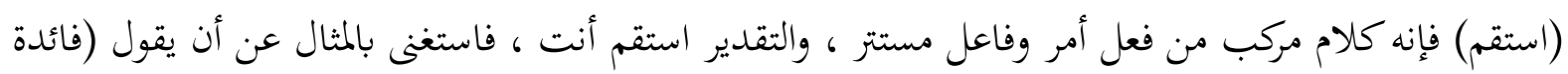

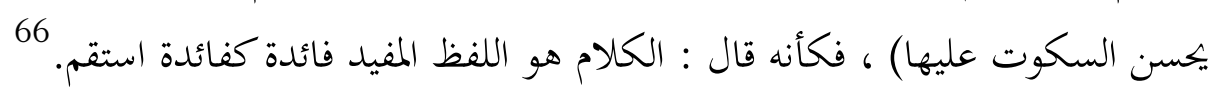

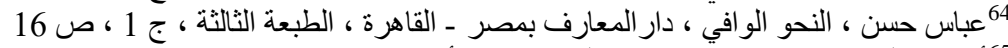

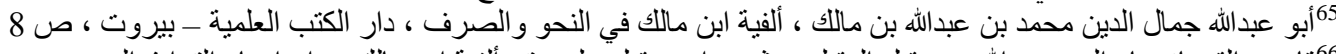

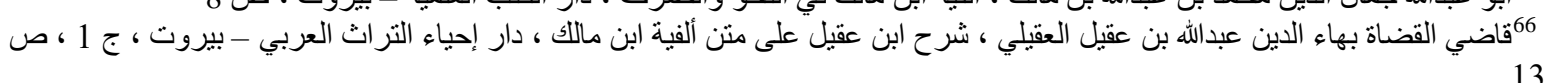




$$
\text { وهناك تعريف آخر يفرق بين الجملة والكلام: }
$$

أ) الجملة هي مركب إسنادي أفاد فائدة وإن لم تكن مقصودة ، كفعل الشرط ، نحو إن قام ، وجملة الصلة

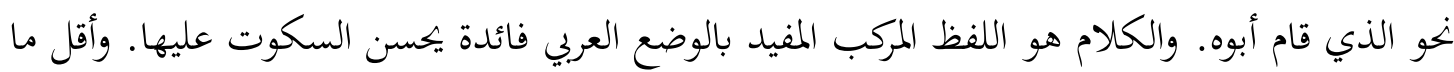

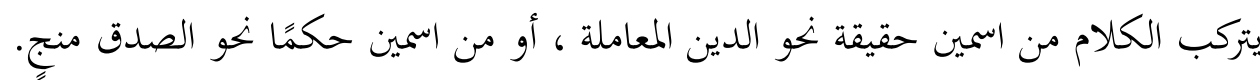

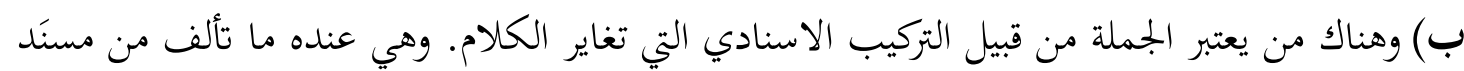

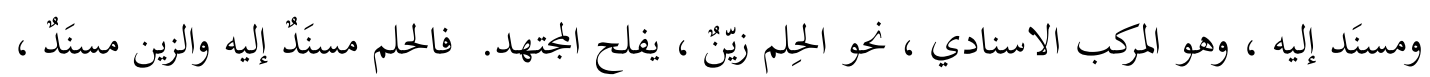

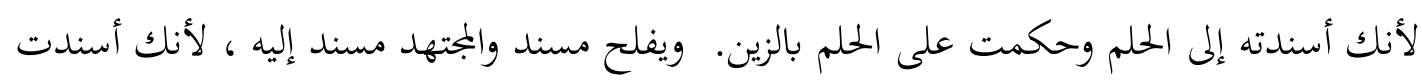
الفلاح إلى المجتهد. المسند إليه هو الفاعل ونائبه والمبتدأ واسم الفعل الناقص واسم الأحرف التي تعمل عمل (ليس) واسم

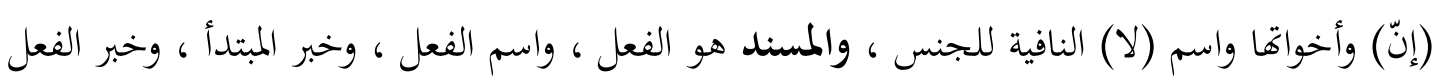
الناقص ، وخبر الأحرف التي تعمل عمل (ليس) ، وخبر (إنّ) وأخواتما. أما الكلام هو الجملة المفيدة معنىً تاثًا مكتفيًا بنفسه ، مثل : رأس الحكمة مخافة الله ، فاز المتقون ، من صدق نجا. اصطلاحات نوية لها ارتباط بكلمة الجملة أ) الكلام، وقد مضى التعربف عنه سابقا. ب) الكَكِم : هو ما تركب من ثلاث كلمات فأكثر ، سواء أكان لها معنى مفيد أم لم يكن لها ما معنى مفيد ،

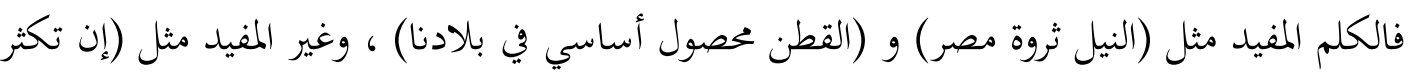
الصناعات...). ج) القول : هو كل لفظ نطق به الانسان ، سواء أكان لفظاً مفردًا أم كركبًا ، وسواء أكان تركيبه مفيدًا أم

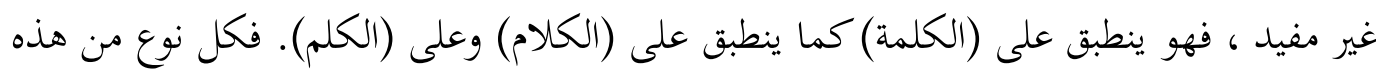

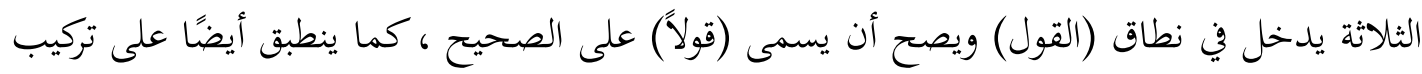

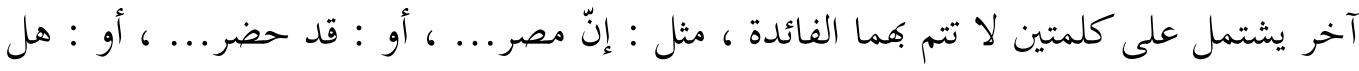

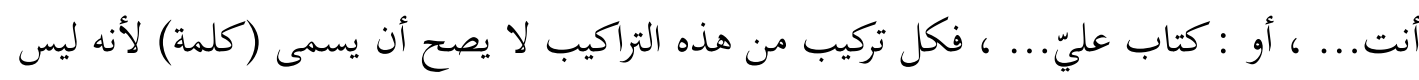

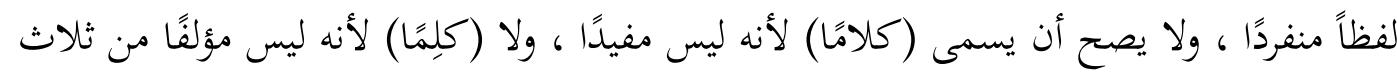
كلمات ، وإنما يسمى قولاً. 67 


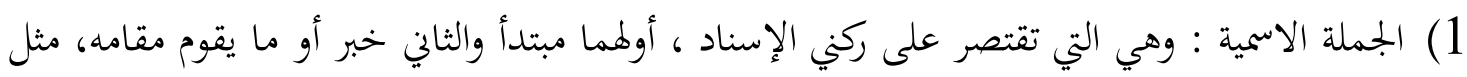
زيدٌ طالبُ ، فاطمة في الفصل.

2) الجملة الفعلية : وهي التي تقتصر على الفعل والفاعل أو ما ينوب عنه ، مثل قامتْ فاطمة، وقُتِلَ زيُّ.

ب) الجملة الكبرى ، وهي ما تتركب من مبتدأ خبره جملة إسمية أو فعلية ، نحو : الزهر رائحته طيبة ، أو الزهر طابت رائحته.

ج) الجملة الصغرى ، وهي الجملة الاسمية أو الفعلية إذا وقعت إحداهما خبرًا لمبتدأ. مثل (رائحته طيبة) من الجملة الكبرى (الزهر رائحته طيبة)

\section{الخاتمة}

إن اللغة العربية تتكون من اللفظ وهو صوت يشتمل على بعض الحروف الهجائية ـ فاللفظ منه ما لا

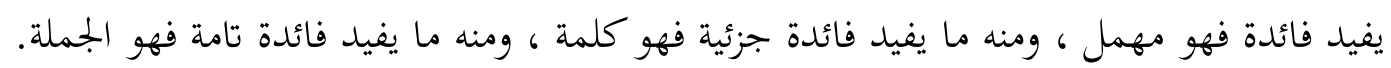
والكلمة إن دلت على معنى في نفسها غير مقترن بزمان فهي الاسم ، وإن اقترن بزمان فهي الفعل ، وإن لم تدل على معنى في نفسها بل في غيرها فهي الحرف.

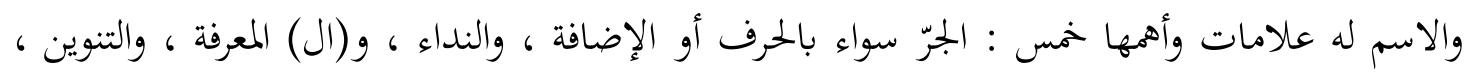

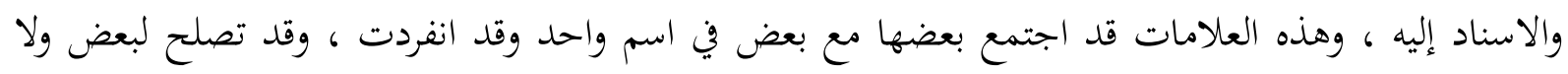
تصلح لآخر.

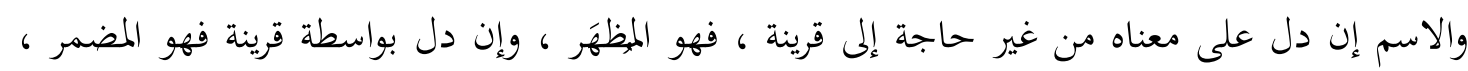

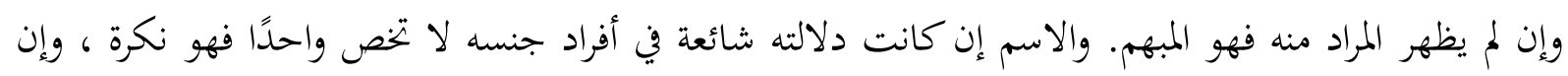
كانت دلالته معينة فهو معرفة.

68 قاضي القضاة بهاء الدين عبدالله بن عقيل ، شرح ابن عقيل على ألفية ابن مالك ، الطبعة العشرون ، دار التراث القاهرة ، 1980م ، ج 1 ، ص 
والكلمة إن دلت على معنى في نفسها مقترن بزمان وضعًا فهي الفعل ، فإن اقترنت دلالتها بزمن ماضٍ

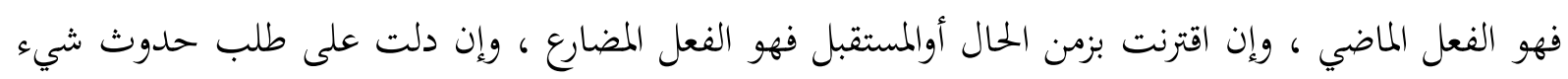
في المستقبل فهو فعل الأمر.

الحرف كلمة تدل على معنى بواسطة غيرها ، بعضها يختص بالأسماء ، والبعض يختص بالأفعال ، والبعض الآخر مشترك بينهما.

الجملة هي ما تركب من كلمتين أو أكثر ، وله معنى مفيد مستقل ، وهي ترادف الكلام. وهي قسمان: الجملة الاسمية والجملة الفعلية.

\section{فهـرس المراجـع}

$$
\text { القرأن الكريم }
$$

أبو عبدالله جمال الدين محمد بن عبدالله بن مالك ، ألفية ابن مالك في النحو والصرف ، دار الكتب

$$
\text { العلمية - بيروت ايو عبلات }
$$

أبو عبدالله محمد بن محمد بن داود الصنهاجي ، متن الأجرومية في النحو ، دار الصميعي- الرياض ،

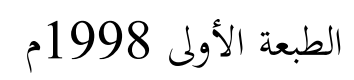

السيد أحمد الهاشمي ، القواعد الأساسية للغة العربية ، دار الكتب العلمية

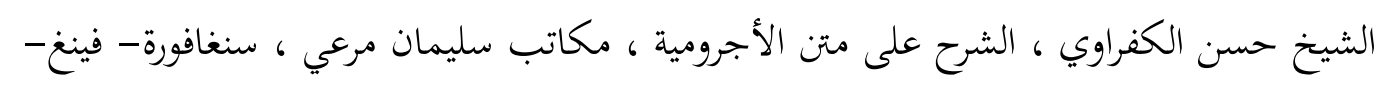
كوتابهارو

سليمان فياض ، النحو العصري ، مركز الأهرام ، الطبعة الأولى ، 1995 م

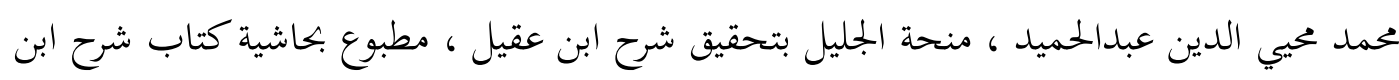

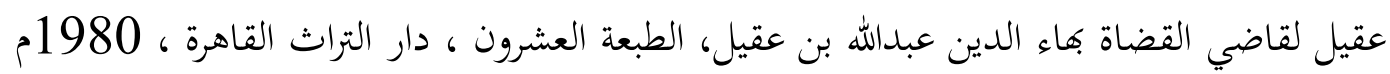

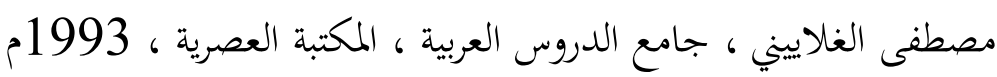

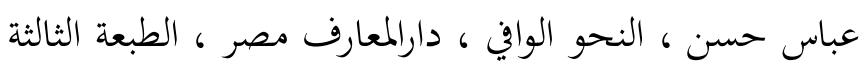

